\title{
Evaluation of Spectrum of Scrotal Pathologies using High Resolution Ultrasound
}

\author{
Narasipur Lingaiah Rajendra Kumar', Athikayula Ashwin Raghavendra², Chakenalli Puttaraju Nanjaraj ${ }^{3}$, \\ Shashikumar M R ${ }^{4}$, Sanjay P, Nishanth RK ${ }^{5}$ \\ ${ }^{1}$ Professor \& Hod, ${ }^{2}$ Resident, Professor, ${ }^{3}$ Professor, ${ }^{4}$ Assistant Professor, ${ }^{5}$ Senior Resident, Department of Radiology, Mysore \\ Medical College \& Research Institute, Mysuru, Chennai India
}

Corresponding author: Athikayula Ashwin Raghavendra, 616/1 Thiruvottiyur High Road, Tondiarpet, Chennai 600081, Tamil Nadu, India

DOI: http://dx.doi.org/10.21276/ijcmsr.2020.5.1.42

BY-NC-ND

How to cite this article: Narasipur Lingaiah Rajendra Kumar, Athikayula Ashwin Raghavendra, Chakenalli Puttaraju Nanjaraj, Shashikumar M R, Sanjay P, Nishanth RK. Evaluation of spectrum of scrotal pathologies using high resolution ultrasound. International Journal of Contemporary Medicine Surgery and Radiology. 2020;5(1):A192-A196.

\section{A B S T R A C T}

Introduction: The scrotum and its contents are normally accessible for clinical examination under normal conditions. Physical examination may be limited by tenderness or swelling. Gray scale and Doppler ultrasound imaging supplements the clinical examination, as an accurate means of evaluating diverse scrotal diseases. It permits differentiation between the lesions like torsion that require urgent surgical management from orchitis which can be managed conservatively.

Material and methods: The study was conducted on 70 patients presenting to the outpatient department of Mysore Medical College and Research Institute, Mysore with symptoms pertaining to the scrotum during a period of 12 months. They were subjected to scrotal ultrasound examination. Frequency and proportion were calculated using Epi Info ${ }^{\text {TM }}$ for Windows version 7.

Results: The most commonly involved age group was 31 to 40 years ( $n=23 ; 32.9 \%$ ). Swelling was the most common symptom. On USG, the most common scrotal pathology encountered was hydrocele $(n=22 ; 19.80 \%)$ followed by epididymal cyst $(n=18 ; 16.2 \%)$, epididymo-orchitis $(n=15 ; 13.60 \%)$ and epididymitis $(n=10 ; 9 \%)$. The pathologies were more common on left side ( $n=48,43.24 \%)$.

Conclusion: High frequency ultrasonography with Color Doppler study serves as an excellent diagnostic imaging modality in the evaluation of scrotal diseases. It is the investigation of choice since it is highly sensitive, easy to perform, widely available, repeatable and involves no risk of ionizing radiation. Periodic follow-up USG scans are recommended for patients with inflammatory scrotal lesions to monitor response to treatment and to reveal the development of complications.

Keywords: Torsion; Epididymo-orchitis; Varicocele; Hydrocele; Epididymitis; Pyocele; Testicular microlithiasis; Epididymal Cyst; Testicular Tumour.

\section{INTRODUCTION}

The scrotum is a musculo-fascial sac containing the testes, epididymis and their appendages. The accessibility of these structures for clinical examination is easy in the absence of any pathology. Most of the diseases that affect the scrotum causing swelling and tenderness limit the clinician to differentiate intra-testicular from extra-testicular lesions and benign from malignant lesions. Acute painful conditions like acute testicular torsion and acute epididymo-orchitis also hamper the accurate diagnosis of the underlying pathology because of overlapping clinical features, thereby requiring prompt diagnosis for providing the necessary treatment. ${ }^{1}$ High-frequency ultrasound is an outstanding modality to evaluate the scrotal wall, epididymis, testes and their appendages as it provides high-quality anatomical detail. High-frequency ultrasound, coupled with colour flow Doppler imaging help in determining the viability and vascularity of the testes, thereby assisting in providing an accurate diagnosis in perplexing situations. ${ }^{2}$

The advantages of ultrasonography in the evaluation of scrotal diseases are - non-invasive, easy reproducibility, rapid evaluation with real time examination capability, easy availability, economical and the lack of radiation. Computed tomography has the disadvantage of ionising radiation to the gonads, requirement for contrast media and is a relatively expensive modality. Magnetic Resonance Imaging (MRI) is also expensive and not readily available, even though it provides improved cross-sectional information. Therefore, USG is the undisputed first choice investigation for scrotal pathologies. $^{3}$

In this backdrop, this study was an attempt to know the distribution of the non-traumatic scrotal pathologies among the subjects and to understand the sonographic characteristics of the spectrum of scrotal pathologies using high-frequency ultrasound and Doppler. 
The aims of the study were to study the pattern of distribution of non-traumatic scrotal diseases among patients attending the out-patient department of Mysore Medical College and Research Institute and to study the sonographic appearance of the spectrum of scrotal diseases.

\section{MATERIAL AND METHODS}

The subjects of this Descriptive study were 70 patients attending the outpatient department of Mysore Medical College and Research Institute with clinical features of scrotal diseases. Study was done for 12 months (1st January 2016 to 31st December 2016).

\section{Inclusion Criteria}

Patients of all age groups with clinical manifestations of non-traumatic scrotal diseases.

\section{Exclusion Criteria}

Post-operative cases

\section{Method of collection of data}

After taking informed consent, all the patients included in the study underwent scrotal ultrasonography using 7.012.0 MHZ high frequency linear array transducer coupled with Colour Doppler in Esaote My Lab 40 and Phillips affinti $70 \mathrm{G}$ equipments. Approval of the research proposal was obtained from the Ethical and Research Committee of Mysore medical college and Research Institute.

Baseline demographic data were recorded, which included the patient's age, symptoms and clinical diagnosis. The ultrasound findings were analyzed with regard to the location and type of the abnormality which included- hydrocele, varicocele, testicular abscess, extra-testicular abscess, epididymal cyst, epididymitis, orchitis, testicular torsion, tumours, scrotal wall thickening, inguino-scrotal hernia and calcifications if any. Subsequently, these cases were followed up and confirmed with either surgical findings, histopathology reports, response to treatment or follow up scans wherever applicable.

\section{STATISTICAL ANALYSIS}

Frequency and proportion were calculated using Epi Info ${ }^{\mathrm{TM}}$ for Windows version 7 and the results were depicted using appropriate graphs, tables and charts.

\section{RESULTS}

The study included a total of 70 patients. The patients most commonly involved were those belonging to the age group of 31 to 40 years $(n=23 ; 32.9 \%)$. The least number of patients belonged to the age group of $0-10$ years $(n=1 ; 1.4 \%)$. The patients from the age group of 21 to 60 years constituted $80 \%$ of the study population.

On USG, the total number of lesions detected were 111. The most common cause of scrotal pathologies was hydrocele $(n=22,19.80 \%)$ followed by epididymal cyst $(n=18,16.2 \%)$, epididymo-orchitis ( $n=15,13.60 \%)$, epididymitis ( $n=10$; $9 \%)$, funiculitis ( $n=9,8.1 \%)$, varicocele $(n=8,7.2 \%)$, pyocele $(n=7,6.3 \%)$, testicular torsion $(n=5,4.5 \%)$, testicular abscess $(n=4,3.6 \%)$, inguino-scrotal hernia $(n=4,3.6 \%)$, testicular microlithiasis $(n=3,2.7 \%)$, testicular tumour $(n=3,2.7 \%)$ and tubercular epididymo-orchitis $(n=3,2.7 \%)($ Fig-1).

The number of scrotal lesions seen on the left side were

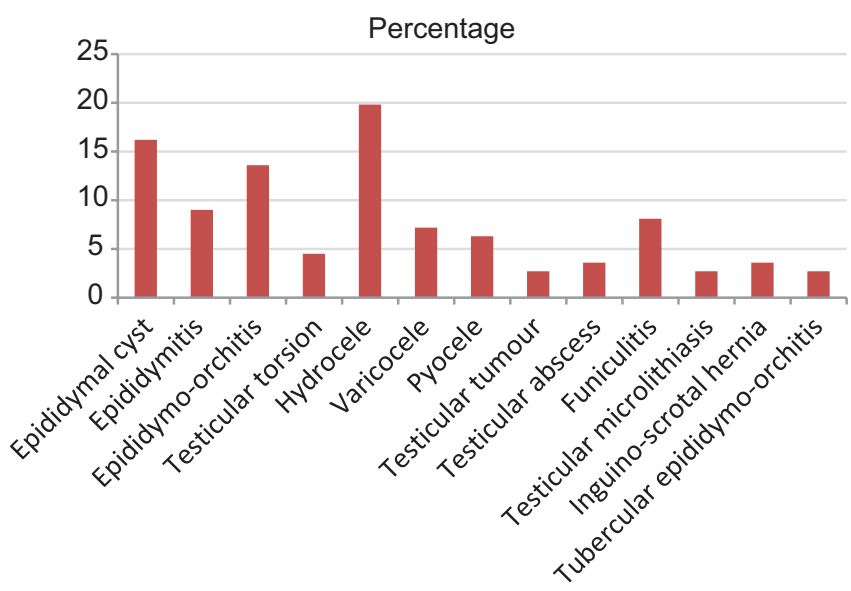

Figure-1: USG diagnosis of various causes of scrotal pathologies.

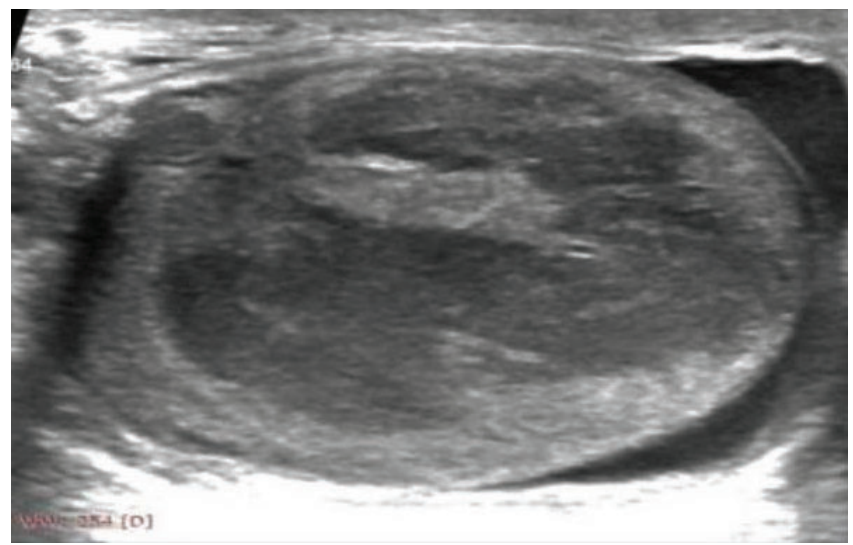

Case-1: Right testicular abscess. Right testis is enlarged with multiple ill-defined hypoechoic areas and internal echoes.

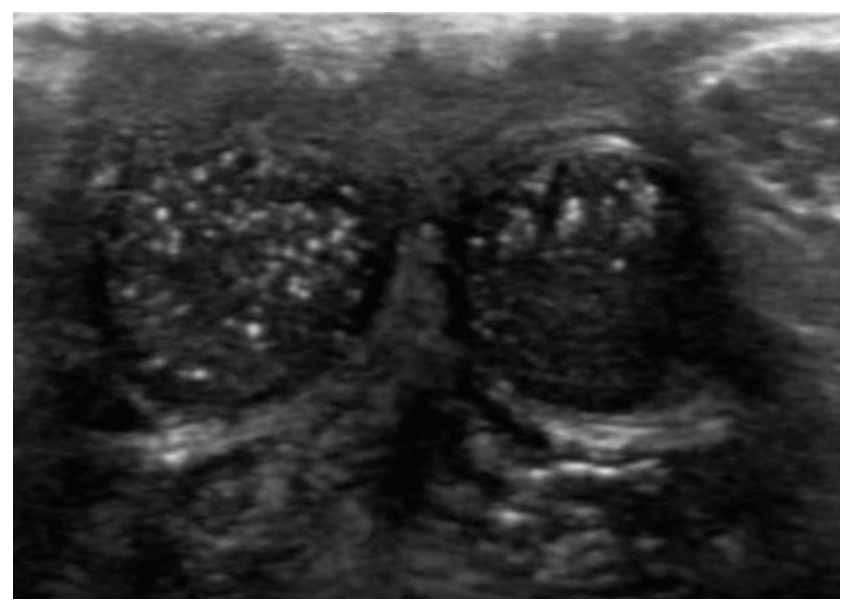

Case-2: Bilateral testicular microlithiasis. Transverse image of both the testes showing bilateral testicular microlithiasis.

48(43.24\%), on the right side were $46(41.45 \%)$ and in bilateral locations were $17(15.31 \%)$. Some patients $(n=32$, 45.71\%) had more than one lesion on either side.

Associated symptoms included swelling, pain, fever and infertility. Almost all the scrotal pathologies were associated with scrotal swelling $(n=68,97.1 \%)$ except in two cases.

Epididymal cysts were seen in 18 patients, 6 patients had right epididymal cysts (33.34\%), 8 patients had left epididymal cysts $(44.44 \%)$ and 4 patients had bilateral epididymal cysts 


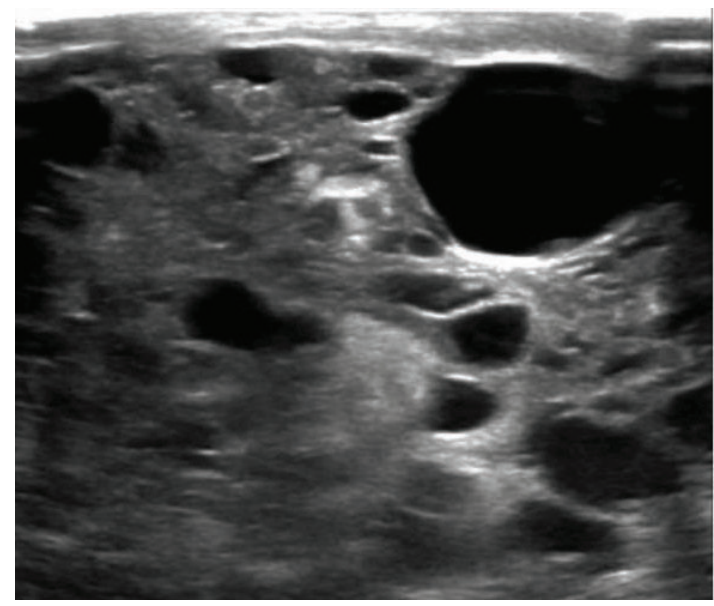

Case-3: Mixed germ cell tumour of testis. Testis is enlarged with multiple cystic spaces and few hyperechoic areas within.

(22.22\%). Only 6 patients had complaints of pain and the size of the cysts in these patients was more than $3 \mathrm{~cm}$. The largest epididymal cyst measured $5.3 \mathrm{~cm}$ in maximum dimension causing distortion of the adjacent testis.

Acute epididymitis $(n=10)$ was more common on the right side. All the patients had enlarged epididymis with hypoechoic echotexture with diffusely increased vascularity. Acute epididymo-orchitis $(n=15)$ was most commonly seen on the left side. Majority of the patients had enlarged testis and epididymis with decreased echotexture and increased vascularity. Epididymis was enlarged in 13 cases (86.67\%), normal in size in 2 cases $(13.33 \%)$. The epididymis showed decreased echopattern in 13 cases $(86.67 \%)$ and increased echopattern in 2 cases (13.33\%). Diffuse increase in vascularity of epididymis was noted in13 cases (86.67\%). Testis was enlarged in 9 cases (60\%), normal in size in 4 cases $(26.67 \%)$ and decreased in size in 2 cases (13.33\%). Testis was hypoechoic in 13 cases (86.67\%) and showed normal echotexture in 2 cases $(13.33 \%)$. Vascularity of testis was increased in 11 cases (73.33\%), decreased in 2 cases (13.33\%) and normal in 2 cases $(13.33 \%)$.

Hydrocele $(n=22)$ was the most common scrotal pathology detected in this study. Among the study population, eight patients $(36.36 \%)$ had right sided hydrocele, seven patients $(31.82 \%)$ had left sided hydrocele and seven patients (31.82\%) had bilateral hydrocele. Among them, one patient was detected to have encysted hydrocele of the right spermatic cord. Hydrocele, as an isolated finding was seen in only ten $(n=10)$ subjects.

Varicocele was most commonly seen on the left side. Four patients had large varicocele and four patients had moderate varicocele. There were 4 patients with complaints of infertility and all 4 had left sided large varicoceles. These patients had dilated tortuous pampiniform plexus with reflux on Valsalva manoeuvre. Patients with large varicocele had a mean pampiniform plexus vein diameter of $6 \mathrm{~mm}$ on the affected side during standing posture. On Valsalva, the diameter increased by $1.7 \mathrm{~mm}$. Those patients with moderate varicocele had a mean diameter of $4.3 \mathrm{~mm}$ in standing position and increased by $1.3 \mathrm{~mm}$ on Valsalva manoeuvre. Pyocele was seen in seven patients. Majority of the patients $(\mathrm{n}=6,85.71 \%)$ had mildly enlarged ipsilateral testis and epididymis

Chronic epididymo-orchitis was seen in three $(n=3)$ patients. Two ( $n=2,66.67 \%)$ subjects had right sided involvement. Heterogeneous echopattern with hyperechoic areas, enlarged epididymis and testis with increased vascularity were seen in all cases. Scrotal wall thickening was seen in all the patients. All three patients had history of systemic tuberculosis. One patient had associated testicular abscess, pyocele with internal septations and echogenic debris. All three subjects were subjected to USG following initiation of ATT. All of them showed good interval response to treatment.

Testicular torsion was detected in five $(n=5)$ patients. Four $(n=4,80 \%)$ patients had right testicular torsion. In all the cases, the testis was hypoechoic, showing reversed orientation with the absence of colour flow.

Testicular abscess was seen in four $(n=4)$ subjects. Right testis was involved in three subjects. All the patients had enlargement of the testis, epididymis with increased vascularity. Hypoechoic areas with internal echoes were noted within the testis. There was an extension of the abscess into the tunica vaginalis in one case. Minimal fluid collection was seen in tunica vaginalis in two cases, likely due to inflammatory reaction. Follow-up USG revealed good response to antibiotics in all patients.

Scrotal tumours were seen in three patients, all involving the right testis. On histopathological examination, they turned out to be seminoma, mixed germ cell tumour and teratoma. Three cases of bilateral testicular microlithiasis were detected as incidental findings. The patients belonged one each, to the first, second and third decade age groups. There were no associated testicular masses detected.

\section{DISCUSSION}

The most commonly involved age group was 31 to 40 years (n $=23,32.9 \%)$ followed by 21 to 30 years $(n=16,22.9 \%)$ and 41 to 50 years $(n=14,20 \%)$. A similar age group distribution of scrotal disorders was also reported by Thinyu et $\mathrm{al}^{4}$ in their study of 110 cases.

Common symptoms were swelling, pain, fever and infertility among which swelling was the most common symptom. There was a total of 111 lesions detected. On USG, the most common cause scrotal pathology was hydrocele $(n=22$, 19.80\%). Arjhansari K, Vises $\mathrm{N}$ et $\mathrm{al}^{5}$ had performed a retrospective study in 72 cases of extra testicular lesions and 48 cases of intratesticular lesions to find out the causes of intra-scrotal disease in which it was reported that hydrocele was the most common pathology.

In our study of 70 patients, 68 patients (97.14\%) had complaints of scrotal swelling, the most common cause being hydrocele. The second most common symptom was pain which was seen in 40 patients $(57.1 \%)$. The most common cause of pain was infective/ inflammatory etiology $(n=29$, $72.5 \%)$. Our study showed similar results when compared to the observations made in other studies where the incidence of scrotal pain in patients with scrotal pathologies ranged from 62 to $76 \%{ }^{6,7}$

Among the subjects with epididymal cysts, the most common age group involved was 31 to 40 years $(n=10,55.55 \%)$ followed by 61 to 70 years $(n=3,16.66 \%)$. The cysts ranged 
from $1.2 \mathrm{~cm}$ to $5.3 \mathrm{~cm}$. Patients with larger cysts, complained of pain $(n=6)$, they revealed no vascularity of cyst wall on CDI. They were treated symptomatically.

There were 10 patients (14.2\%) diagnosed with acute epididymitis. USG features seen were enlarged epididymis in all the patients (100\%), increased epididymal vascularity in 9 patients (90\%) and altered echogenicity in 9 patients (90\%). Other features such as reactive hydrocele and scrotal wall thickening further augment the diagnosis of epididymitis. A similar study done by Smith et $\mathrm{al}^{8}$ reported increased incidence with respect to the enlarged epididymis (71.5\%), however hyper-vascular epididymis was reported in $72.9 \%$ of the cases and associated scrotal wall thickening in $11.3 \%$ cases.

There were 15 patients with acute epididymo-orchitis. Accurate diagnosis of acute epididymo-orchitis was done in all cases. The patients were followed up following administration of systemic antibiotic and there was resolution of ultrasound features in all cases. USG features contributing to the diagnosis were bulky testis and epididymis showing hypoechoic echopattern and increased vascularity in a majority of the cases.

Chronic tubercular epididymo-orchitis was diagnosed in 3 patients. Heterogeneous echopattern with hyperechoic areas, enlarged epididymis and testis with increased vascularity were seen in all cases. Compared to similar cross-sectional studies done by Horstman et $\mathrm{al}^{9}$ and Farriol et $\mathrm{al}^{10}$ in which acute epididymo-orchitis constituted about 40\% of the scrotal pathologies, our study demonstrated acute epididymo-orchitis in only $13.6 \%$ of the study population. Reduced monetary input, limited accessibility to ultrasound and medical facilities compared to the western population and the lack of awareness could be the possible factors for the reduced detection of subjects with epididymo-orchitis inspite of poor socioeconomic status, reduced hygiene in rural areas and increased prevalence of sexually transmitted infections.

Testicular abscess was seen in 4 patients, involving the right testis in 3 patients. Follow-up USG revealed good response to antibiotics in all patients. Testicular abscess occurs as a complication of acute epididymo-orchitis or chronic epididymo-orchitis. Our results are similar to the studies performed by Luker and Siegel. ${ }^{11}$

Hydrocele was the most common lesion detected in our study accounting to about $19.8 \%$ of the total lesions which is comparable to the findings from many other studies, where the incidence of hydrocele has been reported to be about $21 \% .^{3,6}$ Hydrocele was most commonly seen in the age group of 31 to 40 years $(n=6,27.27 \%)$. In 8 patients it was seen on the right side (36.36\%), in 7 patients on the left side $(31.82 \%)$ and 7 patients had bilateral hydroceles $(31.82 \%)$. Out of the 22 patients, 1 patient had encysted hydrocele of the right spermatic cord. Two patients with hydrocele had associated inguino-scrotal hernia, one patient with testicular torsion, three patients with acute epididymo-orchitis, two patients with acute epididymitis, two patients with testicular abscess, one patient with epididymal cyst and one patient with testicular microlithiasis.

Varicocele was seen in eight patients. Seven had left varicocele $(87.5 \%)$ and one had right varicocele. There were 4 patients with complaints of infertility, all of them with left varicocele. Four patients (50\%) belonged to the 21 to 30 years age group. USG features were dilated tortuous pampiniform plexus with reflux of blood on Valsalva manoeuvre. Among the subjects, 5 patients underwent surgery and there was a good correlation with USG and intra-operative findings. However post-operative improvement of patients with infertility could not be evaluated due to lack of follow up. Similar studies reported incidence of varicocele at 9.1\%, 10.9\% and $13.1 \%$ by Tinthyu $\mathrm{M}$ et $\mathrm{al}^{4}$, D'Andrea et $\mathrm{al}^{12}$ and Rizvi et $\mathrm{al}^{3}$ respectively. All the three studies reported that 21 to 30 years as the most common age-group for varicoceles which is similar to our study.

There were 5 cases of testicular torsion of which 4 cases were right sided. The ultrasound features were reversed orientation of the testis, hypoechoic echotexture and no colour uptake on CDI. The spermatic cord at the level superior to the epididymal head revealed characteristic "whirlpool sign", with more than one and a half turns of the spermatic cord. The patients underwent surgery, the testis was non-viable and the type of torsion was intravaginal in all the cases. Vijayraghavan $\mathrm{S}$ et $\mathrm{al}^{13}$ conducted a prospective study of 211 patients with acute scrotum and had concluded that the sonographic realtime whirlpool sign is the most specific and sensitive sign of torsion, both complete and incomplete.

Scrotal tumours were seen in three patients, all involving the right testis. On histopathological examination, they turned out to me seminoma, mixed germ cell tumour and teratoma. The ultrasound findings in our study are similar to those performed by Grantham et al. ${ }^{14}$ Micallef $\mathrm{M}$ and Torreggiani WC et $\mathrm{al}^{15}$ in their study on scrotal swellings concluded that ultrasound examination distinguishes extra-testicular (almost always benign) from intratesticular (potentially malignant) causes of scrotal swelling. Infection, trauma, and torsion mimic the ultrasound appearance of a tumour as do rare benign entities.

Three patients $(2.78 \%)$ had bilateral testicular microlithiasis. The subjects belonged to the younger age group (10 to 30 years). No associated mass lesions were found in these patients. They were found as incidental lesions. In the pediatric population, Goede et $\mathrm{al}^{16}$ noted that the prevalence of testicular microlithasis was $2.4 \%$ in asymptomatic male patients belonging to the $0-19$ years age group, with an increase in prevalence noted with increasing patient age. Cast et $\mathrm{al}^{17}$ calculated a 21.6 -fold relative risk of a concurrent tumour in patients with testicular microlithiasis. Isolated TM has been reported to be associated with germ cell tumours. However further longitudinal studies are required to firmly establish the relationship between testicular microlithiasis and germ cell tumours.

\section{Limitations of the study}

Follow up of few cases pertaining to inflammatory causes of scrotal pathology were not possible.

\section{CONCLUSION}

High frequency ultrasonography with color Doppler study serves as an excellent diagnostic imaging modality in the evaluation of scrotal swellings. It is the investigation of choice as it is highly sensitive, easy to perform, widely available, 
repeatable and involves no risk of ionizing radiation, especially to radiosensitive parts like testis. It helps to arrive at an accurate diagnosis in a majority of patients with scrotal swellings, thus guiding further management. When USG findings are inconclusive MRI may be useful.

Periodic follow-up USG studies are recommended for all patients with inflammatory scrotal lesions for monitoring response to treatment or to reveal development of complications.

\section{REFERENCES}

1. Coley BD. Sonography of pediatric scrotal swelling. Semin Ultrasound CT MR 2007;28(1):297-306.

2. Appelbaum L, Gaitini D, Dogra VS. Scrotal ultrasound in adults. Semin Ultrasound CT MR 2013;34(3):25773.

3. Rizvi SA, Ahmad I, Siddiqui MA, Zaheer S, Ahmad K. Role of color Doppler ultrasonography in evaluation of scrotal swellings: pattern of disease in 120 patients with review of literature. Urol J 2011;8(5):60-5.

4. Thinyu S, Muttarak M. Role of ultrasonography in diagnosis of scrotal disorders: A review of 110 cases. Biomed Imaging Interv J 2009;5(2):e2.

5. Arjhansiri K, Vises N, Kitsukjit W. Sonographic evaluation of the intrascrotal disease. J Med Assoc Thai 2004;87 Suppl 2:S161-7.

6. Siddiqui EH, Siddiqui S, Rasool G, Khan N. Scrotal Pathologies: Role of high resolution \& Doppler ultrasound in evaluation. Professional Med J 2013;20(4):924-28.

7. Agarwal Am, Tripathi PS, Shankwar A, Naveen C. Role of Ultrasound with Color Doppler in Acute Scrotum Management. J Family Med Prim Care 2014;3(6):40912.

8. Smith RP, Tracy CR, Kavoussi PK, Witmer MT, Costabile RA. The impact of color Doppler ultrasound on treatment patterns of epididymitis in a universitybased healthcare system. Indian J Urol 2013;29(5):22-6.

9. Horstman WG, Middleton WD, Melson GL. Scrotal inflammatory disease: Color Doppler US findings. Radiology 1991;179(3):55-9.

10. Farriol VG, Comella XP, Agromayor EG, Creixams XS, Martinez De La Torre IB. Gray-scale and power Doppler sonographic appearances of acute inflammatory diseases of the scrotum. J Clin Ultrasound 2000;28(1):67-72.

11. Luker GD, Seigel MJ. Color Doppler sonography of the scrotum in children. AJR Am J Roentgenol 1994;163(3):649-55.

12. D'Andrea A, Coppolino F, Cesarano E, Russo A, Cappabianca S, Genovese EA, et al.US in the assessment of acute scrotum. Crit Ultrasound J 2013;5:Suppl 1:S8.

13. Vijayraghavan S. Sonographic differential diagnosis of acute scrotum: real time whirlpool sign, a key sign of torsion. J Ultrasound Med 2006;25(6):563-574.

14. Grantham JG, Charboneau JW, James EM, Kirschling RJ, Kvols LK, Segura JW, et al. Testicular neoplasms: 29 tumors studied by high-resolution US. Radiology 1985;157(4):775-80.

15. Micallef M, Torreggiani WC, Hurley M, Dinsmore WW, Hogan B. The ultrasound investigation of scrotal swelling. Int J STD AIDS 2000;11(5):297-302.
16. Goede J, Hack WW, van der Voort-Doedens LM, Sijstermans K, Pierik FH. Prevalence of testicular microlithiasis in asymptomatic males 0 to 19 years old. J Urol 2009;182(5):1516-1520.

17. Cast JE, Nelson WM, Early AS, Biyani S, Cooksey G, Warnock NG, et al. Testicular microlithiasis: prevalence and tumour risk in a population referred for scrotal sonography. AJR Am J Roentgenol 2000;175(1):17031706

\section{Source of Support: Nil; Conflict of Interest: None}

Submitted: 11-01-2020; Accepted: 29-02-2020; Published online: 14-03-2020 